\title{
Erythema nodosum progressing to pyoderma gangrenosum as a complication of Crohn's disease
}

\author{
ANDREW GELLERT \\ M.B., B.S., M.R.C.P. (U.K.) \\ E. S. GREEN \\ M.A., M.B., B.S. \\ ERIC R. BECK \\ C. M. RIDLEY \\ M.B., F.R.C.P. \\ B.M., F.R.C.P.
}

Departments of Gastroenterology and Dermatology, Whittington Hospital, Highgate Hill, London N19 5NF

\section{Summary}

Erythema nodosum occurs more frequently than pyoderma gangrenosum in Crohn's disease. We report the occurrence of both lesions in a woman with Crohn's disease and the transformation of one to the other. Pyoderma gangrenosum has been described at the site of previous trauma in Crohn's disease and at the site of other skin conditions in other circumstances, but, to the best of our knowledge, actual progression from erythema nodosum to pyoderma gangrenosum has been reported on only one previous occasion in Crohn's disease.

KEY WORDS: erythema nodosum, pyoderma gangrenosum, Crohn's disease.

\section{Introduction}

This case report describes the progression of erythema nodosum to pyoderma gangrenosum in a case of Crohn's disease.

Pyoderma gangrenosum is classically associated with ulcerative colitis and is rare in Crohn's disease; erythema nodosum, on the other hand, occurs significantly more commonly in Crohn's disease (Greenstein, Janowitz and Sachar, 1976). Progression from one to the other is very unusual.

\section{Case report}

A 30-year-old Greek Cypriot woman presented in 1972 with diarrhoea and erythema nodosum. Radiological investigations of the gastrointestinal tract at that time were normal. In 1975, a barium followthrough showed narrowing of the terminal $4 \mathrm{~cm}$ of the ileum and a barium enema revealed evidence of colitis with mucosal oedema and irregularity but rectal sparing. Rectal biopsy demonstrated infiltration of the lamina propria with lymphocytes and plasma cells, and a non-caseating granuloma compatible with Crohn's disease.

Over the next 7 years, the clinical course was punctuated by numerous episodes of diarrhoea and abdominal pain, almost invariably heralded by an eruption of typical erythema nodosum and sometimes arthritis in the neck, shoulders and sternoclavicular joints. Symptoms responded well to oral prednisolone, but reduction of the daily dose to less than $10 \mathrm{mg}$ precipitated an exacerbation. Sulphasalazine was added in 1979.

In December 1981, there was a new eruption of erythema nodosum on both shins with widespread arthritis but without accompanying gastrointestinal symptoms. All but one of the painful lesions responded to prednisolone, $30 \mathrm{mg}$ daily. This remaining lesion on the right shin developed irregular exudative ulceration with typical small, punched-out holes, and a similar lesion appeared on the right calf (Fig. 1). A clinical diagnosis of pyoderma gangrenosum was made.

Treatment with prednisolone, $30 \mathrm{mg}$, and dapsone, $200 \mathrm{mg}$ daily, in addition to bed-rest and topical paraffin gauze led to resolution and healing.

\section{Discussion}

Four of the 5 patients in the original description of pyoderma gangrenosum described by Brunsting had ulcerative colitis (Brunsting, Goeckerman and O’Leary, 1930).

Perry (1969) reported that 31 of his 62 patients with pyoderma gangrenosum had ulcerative colitis. Pyoderma gangrenosum has been reported in Crohn's disease, but in only 7 cases prior to 1968 (Van Pattar et al., 1954; Perry and Brunsting, 1957; Chapin et al., 1956; Parks, Morson and Pegum, 1965; Bishopric and Bracken, 1964; Stathers, Abbott and McGuinness, 


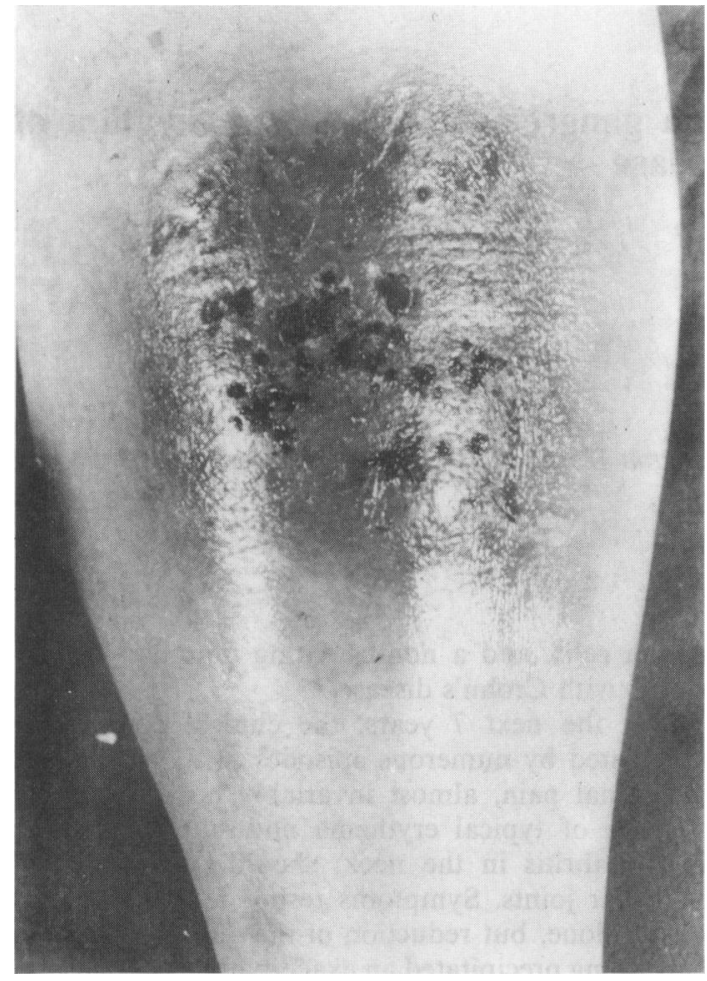

Fig. 1. Photograph of right shin and calf showing lesions of pyoderma gangrenosum and erythema nodosum.

1967; McCallum and Kinmont, 1968). At least a further 11 cases have been reported (Greenstein, Janowitz and Sachar, 1976; Finkel and Janowitz, 1981; Hickman and Lazarus, 1980) although the rarity of the association was underlined by Greenstein et al. (1976) who reported an incidence of $1.2 \%$ (6 cases) in a series of 498 patients with Crohn's disease over 10 years, compared with an incidence of $5 \%$ (10 cases) in a series of 202 patients with ulcerative colitis over the same period. The authors emphasised that all extra-intestinal complications of Crohn's disease were commoner when the colon was involved and indeed such complications occurring in Crohn's disease confined to the small bowel were significantly less common than among any other patient group in their study. Our patient certainly has strong evidence of colonic disease.

The pathogenesis of both erythema nodosum and pyoderma gangrenosum is poorly understood. Erythema nodosum has been attributed to sulphasalazine therapy in 4 instances (Committee on Safety of Medicines, personal communication), although the fact that our patient suffered from erythema nodosum for 7 years before receiving the drug makes this association unlikely in her case. We know of no reports of pyoderma gangrenosum attributable to sulphasalazine therapy. Erythema nodosum is a 3 reaction to many provoking agents and results from $\stackrel{\varnothing}{\varrho}$ the deposition of immune complexes in dermal $c$ venules. The histological findings are variable and $\overrightarrow{\vec{F}}$ non-specific with features of small vessel damage and $\stackrel{\mathcal{D}}{\rightarrow}$ panniculitis.

Pyoderma gangrenosum is a destructive, necrotiz- $\frac{\bar{\sigma}}{\bar{c}}$ ing ulceration of the skin (Ryan and Wilkinson, $\vec{\nabla}$ 1979). Histological changes again tend to be non- $\triangle$ specific but show venous and capillary damage and $ळ$ sterile abscess formation. The Schwartzmann reac- $\overrightarrow{0}$ tion is invoked by many workers who suggest an inability of a compromised reticuloendothelial sys- $\vec{\omega}$ tem to protect the tissues from a second insult (Ryan, $\frac{D}{\circ}$ 1970). An overlap exists in Behçets syndrome where ulcers may be heralded by lesions of erythema nodosum (Ryan, 1970).

Du Boulay and Whorwell (1982) have recently के reported 2 patients with Crohn's disease who developed tender, firm lumps on the legs. Unlike the $\circlearrowleft$ cutaneous manifestations in our patient, these erup- 0 tions of 'nodular necrobiosis' persisted for years, never faded, and were unaffected either by the $\vec{\nabla}$ activity of the disease or the medications taken. It is $\stackrel{\mathbb{D}}{\circ}$ of interest that in one patient spontaneous ulceration $\frac{\mathbb{S}}{3}$ and healing occurred and in the second ulceration occurred in one area after minor trauma, but thefe was no progression to pyoderma gangrenosum. $\overrightarrow{0} \vec{\emptyset}$

It has been recognised that pyoderma gangrenof: sum may appear at the site of a pre-existing sk condition (Ryan and Wilkinson, 1979) or at the site of antecedent trauma in Crohn's disease (Finkel and Janowitz, 1981), but a review of the literature has revealed only one case in which erythema nodosum $\mathbb{\perp}$ has progressed at the same site to pyoderma gangrenosum (Stathers et al., 1967). This transformation was observed in our patient.

\section{References}

BISHOPRIC, G.A. \& BRACKEN, J.S. (1964) Pyoderma gangrenosum as the presenting sign of regional enteritis: observations regarding the pathogenesis of the skin lesions. Southern Medical Journal, 57, 675.

Du Boulay, C. \& WhORWELl, P.J. (1982) Nodular necrobiosis: a new cutaneous manifestation of Crohn's disease? Gut, 23, 712.

BRUNSTING, L.A., GoECKERMAN, W.H. \& O'LeARY, P.A. (1930) D Pyoderma (ecthyma) gangrenosum: clinical and experimental 을. observations in five cases occurring in adults. Archives of $\mathrm{N}$ Dermatology, 22, 655.

Chapin, L.E Scudamore, H.H Baggenstoss, A.H \& Bargen, J.A. (1956) Regional enteritis: associated visceral changes. Gastroenterology, 30, 404.

FINKEL, S.I. \& JANOWITZ, H.D. (1981) Trauma and the pyoderma gangrenosum of inflammatory bowel disease. Gut, 22, 410.

GreENSTEIN, A.J., JANOwITZ, H.D. \& SACHAR, D.B. (1976) The extra-intestinal complication of Crohn's disease and ulcerative $\mathbb{\Phi}$ colitis: a study of 700 patients. Medicine, 55, 401.

HICKMAN, J.G. \& LAZARUS, G.S. (1980) Pyoderma gangrenosum: a 
reappraisal of associated systemic diseases. British Journal of Dermatology, 102, 235.

MCCallum, D.I. \& KINMONT, P.D. (1968) Dermatological manifestations of Crohn's disease. British Journal of Dermatology, 80, 1.

Parks, A.G., Morson, B.C. \& Pegum, J.S. (1965) Crohn's disease with cutaneous involvement. Proceedings of The Royal Society of Medicine, 58, 241.

PERRY, H.O. \& BRUnSTing, L.A. (1957) Pyoderma gangrenosum: a clinical study of nineteen cases. Archives of Dermatology, 75, 380.

PerRY, H.O. (1969) Pyoderma gangrenosum. Southern Medical Journal, 62, 899.

RYAN, T.J. (1970) Microvascular injury. Pyoderma gangrenosum and phagedenic pyoderma. In: Major Problems in Dermatology, Vol. 7, p. 322. W. B. Saunders, Philadelphia.

RYAN, T.J. \& WILKINSON, D.S. (1979) In: Textbook of Dermatology. (Eds. A. Rook, D. S. Wilkinson and F. J. G. Ebling), 3rd edn., p. 993. Blackwell Scientific Publications, Oxford, London.

StATHERS, G.M., ABbotT, L.G. \& MCGuinNeSS, A.E. (1967) Pyoderma gangrenosum in association with regional enteritis. Archives of Dermatology (Chicago), 95, 365.

Van Pattar, W.M., Bargen, J.A., Dockerty, M.B., Feldman, W.H., MaYo, C.W. \& WaUGH, J.M. (1954) Regional enteritis. Gastroenterology, 26, 347.

(Accepted 2 February 1983) 